(WOM 2015 manuscript WOM2015-D-14-00080 revised)

\title{
How common is the steady-state? The implications of wear transitions for materials selection and design
}

\author{
Peter J. Blau, PhD \\ Blau Tribology Consulting \\ Biltmore Lake, NC 28715 USA
}

\begin{abstract}
Like other forms of mechanical damage, wear may progress in stages, the length and severity of which depend upon the type of wear and the nature of the tribosystem. Wear rates, wear coefficients, and wear factors are commonly reported as normalized quantities whose units imply a linear relationship with variables like sliding distance, number of repetitive cycles, elapsed time, and normal force. Unfortunately, such implied linearity can be misleading in designspecific material selection. Examples of non-linear wear characteristics are provided for erosive wear, abrasive wear, fretting wear, and non-abrasive (also known as 'adhesive') wear. The differences between a system-specific, linearized wear rate and the instantaneous wear rate will be discussed, as will the difference between sequential and simultaneous wear transitions. The practice of linear normalization ignores such phenomena as incubation periods, running-in, and post-steady-state transitions, leading to misleading dependencies of wear rates on the sliding distance and sampling interval. Some current ASTM testing standards, notably those on erosion testing, account for the non-linear behavior of wear, but others, like tests for sliding wear, usually do not. This paper discusses non-linear wear behavior of several kinds, how the data can be treated, how wear rate notation can be improved, and how recognizing certain non-steadystate behavior can improve the basic understanding, modeling, and testing of wear.
\end{abstract}

Key words: wear, abrasive wear, adhesive wear, erosion, fretting

\subsection{Introduction}

The standard definition of 'wear' [1] describes it as the progressive loss or displacement of material as a result of relative motion between surfaces or a surface and another substance; however, that definition does not require that the loss or displacement take place at a constant rate. In fact, there are frequent situations, both in machines and in laboratory experiments, in which the rate of wear changes with time, number of cycles, or sliding distance. For the purposes of this discussion, there are two types of wear transitions: (1) induced transitions, in which the operator or external disturbances to the tribosystem change its operating conditions (e.g., load, speed, acceleration, environment) and (2) natural transitions, in which the materials or tribosystem change without external stimulus. Type 1 transitions can also be induced by external changes in temperature, ingested debris, or vibrations from another piece of equipment that has 
been turned on. Tribo-corrosion from the surrounding environment can also induce transitions in wear. Examples of Type 2, natural transitions, include running-in, loss of an initial protective film, wear-through of a protective coating, and thermally-induced transitions from the build-up of frictional heat [2]. A common example of a natural transition is scuffing in which gradual loss or degradation of a lubricant leads to solid contact, increased friction, and the onset of wear.

This paper addresses Type 2, non-induced transitions. These have significant implications for the calculation of wear rates and the prediction of wear lives. The details of how and why such wear transitions occur is a subject of continuing relevance in tribo-testing and material selection. Designers and material developers too often rely on a tabulated wear rates or wear coefficients obtained in tests that do not adequately simulate field conditions in which more than one steady-state wear rate can exist. The discussion that follows will show how wear rates can be annotated, modeled, or limited to specific operating ranges and thus improve their utility.

Most forms of wear can exhibit transitions. They include erosion and abrasion as well as impact wear and rolling contact. In his 1980 handbook article on design considerations related to sliding wear Peterson [3] described a number of non-linear effects of variables like load and sliding velocity, and time. Mechanistically, the 'wear history' of a tribosystem can behave analogously to the progression of mechanical damage like fatigue in which a sequence of crack initiation, crack propagation, and failure occurs [4,5]. Also analogous to fatigue, wear rates tend to exhibit statistical behavior, making it advisable to avoid making broad conclusions based on only one or two experiments performed under limited conditions. In the author's experience, the time to reach a transition point in wear rate can sometimes vary from one experiment to the next, even when starting with similar materials and test conditions. Therefore, whatever the combination of units the researcher uses to report wear (using terms like wear factor, wear coefficient, or wear rate), the occurrence of transitions can affect data repeatability.

Some researchers report wear in terms of 'raw' values like total mass or volume change, but others involve normalized or combined units that imply linear relationships between applied variables, like load and sliding distance, and the resultant wear. For example, Table 1 compares the units used to express wear and wear rate in two international conferences held more than 25 years apart [6,7]. In the case of sliding (adhesive) wear alone, 23 units or combinations were used to measure wear in a 1987 proceedings, and 26 years later, the number of units and combinations was 19 ([7]). The message from Table 1 is that wear continues to be expressed in many ways and that some of them presume linear relationships even without experimentally verifying that such linear relationships are exist.

\section{(Insert Table 1)}

Despite a number of attempts, the wear research community has not standardized on the units used to report wear, making it difficult to compare results from one study to another even when the form of wear being studied is the same. For laboratory research, it may make sense to standardize on units, but for specific engineering applications, the units are chosen based on the material's function. Examples include an increase in the clearance in a journal bearing or the time-dependent loss of pressure from a worn gas seal. Therefore, there are good reasons to standardize units usage for research, but not always for applied work and component simulation.

The purpose of this paper is to illustrate the occurrence of Type 2 natural transitions in several forms of wear using examples both from the literature and from the author's prior work. Particular attention is given to fretting wear and sliding wear. Within Type 2, wear transitions 
can occur in a sequence of stages, like the incubation that precedes wear-in which leads to steady-state and eventual wear-out. More interestingly, the progression of wear can be occurring at different rates at different locations even on the same wear scar. Reporting, modeling, and characterizing transitions from one steady-state to another challenges our basic understanding of wear, but it also has practical implications for material selection and modeling of engineering systems.

\subsection{Examples and analysis of non-steady-state wear phenomena}

For the purposes of discussion, two type of wear rates will be distinguished: (1) the system specific wear rate (SSWR) and (2) the instantaneous wear rate (IWR). The SSWR reflects the normalized wear depth or volume or mass loss that is observed for a specific tribosystem, be it a bench-scale test or a field application, after a pre-selected period of operation. For example, for a given-sized lubricated plain bearing run under comparable conditions for a set period of operation (expressed as time, cycles, or sliding distance), there will be a measured volume loss, diametral change, or mass loss. A set of materials or lubricants can then be compared after running for time $t$, and their wear rate $[\operatorname{SSWR}(\mathrm{t})]$ can be expressed as the total wear loss divided by a parameter involving the fixed time $t$. That approach ignores wear-in and any other changes that occur up to the point when the measurement is taken. In other words, SSWR is independent of the path taken from the starting point to the point of final measurement.

By contrast, the IWR reflects the rate of material loss during an small increment of operation. In principle, it is the slope of the tangent to a plot of wear loss versus running time, cycles, or sliding distance at one particular point. The IWR may change quickly during initial sliding, then increase or decrease to a value characteristic of the long-term steady-state. The following examples of different kinds of wear make use of these SSWR and IWR concepts.

2.1 Non-linear wear behavior during erosion. The progression of damage during erosive wear by solid particles or liquid droplets is known to occur in stages. For example, Heymann [8] describes five different varieties of cumulative erosion versus time behavior for liquid impingement. Four out of five are preceded by an incubation period. One of the most common forms of behavior (shown in Figure 1) begins with an incubation period and is followed by an acceleration (maximum erosion rate) and a lower, terminal erosion rate. These and other rates correspond to a piecewise break-down of erosion versus time behavior into stages. These stagespecific rates are defined in an ASTM terminology standard G40 [1]. Likewise, ASTM standard test method G73 [9] provides graphical guidelines for determining the erosion rates on cumulative erosion time curves. Notably, the first standard approved by ASTM's Committee G2 on Erosion (now called the "Committee on Wear and Erosion") in 1972 recognized that in liquid cavitation erosion, up to five stages of damage can occur.

\section{(insert Fig 1)}

Solid particle erosion can also exhibit transitional behavior. Hutchings [10], for example, points out that a ductile material can gain weight initially during erosion as the particles embed, then begin to lose weight as material is subsequently removed. Thus, if expressed as mass loss per unit mass of erodent, the IWR could take on a negative value for a short time. 
To simplify the compilation of erosion data and in order to compare materials, the concept of a normalized erosion resistance has been used [8]. The material loss for a given sample is divided by that lost by a reference sample tested under the same exposure conditions. This dimensionless ratio does not imply that the erosion process is linear, but like the SSWR, it is path independent and based only on measurements at an end point. Thus, given a set procedure, the erosion behavior of one material relative to another can be compared. In more recent interlaboratory studies of the rain erosion of coatings at three different testing facilities [11], the duration of the incubation period, rather than the normalized erosion rate, was selected as the most useful measurement. Therefore, a material's resistance to the onset of damage, based on the duration of a negligible initial IWR, found use as a practical engineering metric.

\subsection{Non-linear wear behavior during two-body wet abrasion}

At Wear of Materials 2013, Blau and de Hoff [12] described how two-body abrasive wear rate can decrease as the abradant is continually reused. Tap-water-lubricated two-body abrasion tests were performed using a series of experimental Fe-Cr-Mo-W-B alloys. Each test disk (diameter $25.4 \mathrm{~mm}$ and thickness $6.4 \mathrm{~mm}$ ) was slid upon its outer rim, tangent to the plane of a rotating abrasive platen that was continually flushed with tap water. The platen contained an adhesive-backed 180 grit-size $\mathrm{SiC}$ grinding paper. A normal force of $5 \mathrm{~N}$ and a surface speed of $1.06+/-0.02 \mathrm{~m} / \mathrm{s}$ were used. Wear was measured by weight loss after set periods of $50 \mathrm{~m}$ of sliding. A new location on the edge of each test disk was used for each subsequent test, but the abrasive paper on the platen was not changed.

Table 2 shows the wear losses for each $50 \mathrm{~m}$ increment, and calculates two wear rates (in mg loss per $m$ sliding distance) for each case. The first wear rate (Wi) assumes that the wear test was conducted that for the given increment of sliding. The second wear rate (Wc) gives the total mass loss to that point and uses the cumulative sliding distance up to that point. The right-hand column lists, as a percentage, the ratio of the cumulative wear rate to the wear rate for the first increment in which fresh, unused abrasive paper was used. In five increments of successive use, the effectiveness of the abrasive paper in removing the steel from the disk reduced by more than $25 \%$. This kind of natural, Type 2 wear transition is not an abrupt one, but rather reflects the effects of attritive wear of abrasive grains on the wear of the steel. In addition to abradant changes, this type of test geometry effects wear in another way. As the disk edge wears, the wear scar widens, and therefore the nominal contact pressure on the wear scar decreases with time. Using a new starting position on the disk circumference for each $50 \mathrm{~m}$ increment of testing was done to compensate for that area effect.

(insert Table 2)

Earlier studies of abrasive running-in showed a similar phenomenon with the frictional changes during stroke-by-stroke dry abrasion tests of a metal, a ceramic, and a polymer [13]. The causes for such transitional behavior include the tip wear/fracture of the initially sharp abrasive grains and the filling of the space between abrasive grains by swarf (wear debris) which reduces their cutting efficiency.

Like the experiments described above, some ASTM test methods, like the 'loop abrasion test' [14], also use continuous sliding over the same abrasive (a continuous belt). The test time is fixed at $3600 \mathrm{~s}$ and therefore the result represents a SSWR. In other standards, such as a version 
of the pin-abrasion test [15], the pin contact point on the abrasive medium is continually changed to provide fresh, unworn abradant into the contact area. Sliding distance-induced transitions in wear rate are therefore suppressed when fresh abrasive is introduced continually. While the abradant is continually wearing-in, the pin is not, and the behavior being measured in such tests would apply mainly to wear involving fresh abradant.

Discussions among the ASTM committee have revealed that some users of the pin-ondrum abrasion test mount two pins, a witness specimen of known abrasion behavior and the test piece, side by side. Both are traversed along the rotating drum to form a pair of spiral wear tracks. In this way, the reference specimen serves to establish that the fresh abradant is behaving as expected and the test sample's wear can be more confidently compared with previous data.

\subsection{Non-linear wear behavior during fretting wear}

Fretting wear is a special case of oscillating sliding wear and it is typically said to occur with amplitudes of approximately $20-200 \mu \mathrm{m}$, although that range is somewhat debatable since the onset of fretting also depends on clamping force (load), frequency, and other factors [16]. Natural transitions in fretting can occur as third-bodies are formed within the confines of the contact. As wear occurs, the contact can loosen, changing the normal force with time. There is a special case of tribo-corrosive fretting that occurs in situations like heat exchangers (tubes against tube sheets) and light water nuclear reactor cores (clad fuel rod against support grids). The latter application can be used to illustrate how multi-stage wear models can be developed to depict certain transitional behavior in fretting wear.

In 2014, the present author considered the challenging problem of a clad nuclear fuel rod fretting against its support grid by flow-induced vibration from pressurized reactor core coolant [17]. This phenomena is referred to in the nuclear industry as grid-to-rod fretting (GTRF). It was proposed during this work that three stages, separated by natural transitions, occurred after a fresh rod bundle is installed and the reactor is brought into operation:

1) Stage 0 (no wear) - either the fuel rod is fully clamped to prevent motion, or a gap exists between it and the grid

2) Stage 1 (wear of the outer layer of the cladding) - wear-through of the natural oxide on the cladding or through a coating or protective layer placed on the rod cladding

3) Stage 2 (wear of the substrate alloy after the outer layer is worn through)

In the proposed, three-stage wear model [17], the initial transition to the onset of fretting was assumed to result from a decrease in the clamping force as the reactor heats up and the spring load holding the rod against the grid relaxes under that heat. When the clamping force reduces to allow relative motion, fretting begins from flow-induced vibration. Then an initial volumetric wear rate, characteristic of a self-mated oxidized Zr-based alloy (known as Zircaloy-4), continues until several micrometers of oxide wears through. At that time, the volumetric wear rate (and friction coefficient) rises to the higher sliding wear rate characteristic of the substrate.

The approach presumes that the wear volume is generated from a certain quantity of frictional work (friction force $(F)$ times the incremental sliding distance $(x)$ given by the average relative velocity and time). This work $(F x)$ is then dissipated over the instantaneous contact area and the resulting wear volume per unit of frictional work produces an increment of depth $(z)$ into the tube cladding. Since the cladding is in essence a cylindrical tube and the counterbody is 
assumed to be a flat spring pressed against it, the wear scar on the tube widens and thereby reduces the contact pressure with time. Also, the deeper the wear scar, the more volume must be removed to increase the depth by a given amount. Thus, a flat plane wearing through a cylinder at a constant volumetric wear rate produces curved wear depth versus time plots, as shown in Figure 2. The assumptions and details of GTRF model are described more fully in Ref. [17]. Incidentally, the length of stage 0 was estimated from published data on early cladding leaks, and the magnitudes of the wear factors for the next two stages were based on a literature survey of the wear of zirconium oxide and zirconium alloys, respectively.

(insert Fig 2)

GTRF is clearly a complex phenomenon that occurs in some designs of nuclear power plants and has the potential to produce leaking fuel rods ('leakers'). Recognizing the presence of natural wear transitions and accounting for more than one steady-state period with a SSWR, is felt to be a more realistic approach to understanding and modeling the effects of reactor operating conditions on wear life.

\subsection{Non-linear wear behavior during sliding}

While the non-linear behavior of wear as a function of exposure time has been long been recognized in erosion testing, wear data for non-abrasive wear (in metals, sometimes called 'adhesive' wear) is often treated as being linear. Significantly, studies of running-in (e.g. [1821]) depart from that assumption, but studies of running-in and sliding wear transitions are relatively rare.

Figure 3 depicts schematically, typical sliding wear behavior such as that typically observed for either a pin-on-disk or flat block-on-ring. Curve " $\mathrm{A}$ " is a general representation of the wear of a sliding metal couple in which the volume loss increases rapidly during wear-in, then reduces in intensity during the steady-state period and increases again during the 'wear-out' stage. Curve " $B$ " illustrates the case where some period of mild wear, such as the wear through of an oxide film or coating, precedes the transition to substrate-dominated wear. At lower applied normal force, initial transients tend to persist longer, but with higher loads, the wear-in occurs almost at once and initial transitions may not be observed. Different materials exhibit different wear-in behavior and the length of the incubation period prior to the onset of wear-in will obviously affect the apparent wear rate if the latter is based only on the volume measured at the end of a set testing time (i.e., the SSWR).

\section{(insert Figure 3)}

Figure 4 depicts how the duration-normalized wear rates (i.e., slope of the curve connecting the beginning of the test with its endpoint) can be very different depending on the interval chosen to define the test duration. For example, line OA represents the case where the test ends only after a transition to a high rate of wear-out. The slope of that line is clearly affected by the wearout phase. On the other hand, a very short test with a slope of line OB, represents a high wear-in rate. Test $\mathrm{OC}$ ends a short time after running at steady-state, and is biased by the major portion of time spent wearing in. The line CD represents the steady-state wear rate (SSWR) in this case, 
but cannot account for the material lost during wear-in. Interestingly, only twice does the IWR happen to be equal to the nominal wear rate that is calculated from a measurement at the end of the test (Figure 4, line OA). These are at points tangent to the cumulative wear volume curve that lie at the change in slope between points OB and OC and also after OD. Therefore, using the endpoint of the test to report a wear rate only reflects the IWR at two times in the tribosystem's wear history.

\section{(insert Figure 4)}

Figures 3 and 4 depict sequential Type 2 transitions, but there is a rather common situation in non-conformal ball (pin)-on-disk testing in which sliding time-dependent wear transitions occur in parallel. In that case, transitions can begin at different sliding times at different radial locations relative to the center the wear track [22]. Consider for example the circular wear track of a pin-on-disk test in which the 'pin' is a fixed hemisphere. Assuming that wear occurs on both bodies, a flat spot develops on the pin and a groove of increasing width $(w)$ appears on the disk. While the effect might be expected intuitively, Mecklenburg [23] confirmed, using an M10 pin sliding on an M-10 tool steel disk lubricated by $\mathrm{MoS}_{2}$, that an increase in track width and a decrease in the nominal contact pressure occurred with sliding distance. Twenty-seven years later [24], Ajayi and Erck modeled the instantaneous nominal contact pressure on the pin $\left(P_{\text {nom }}\right)$ as a function of the initial Hertz contact pressure $\left(P_{H}\right)$, for dry and lubricated pin-on-disk testing of five material pairs. They represented the data with the following expression:

$$
P_{n o m}=P_{H} X^{k}
$$

where $X$ is sliding distance, and $\beta$ and $k$ are empirical constants. Assuming a circular pin/disk contact area of radius equal to half the wear track width, and using the constants reported by Ajayi and Erck for dry sliding and for fully-flooded sliding with a polyolester based synthetic oil with AISI 52100 steel pairs, Eqn (1) was used to calculate the wear track width $w$ as a function of sliding distance as follows:

$$
w=\frac{4 L}{P_{\text {nom }}} \div
$$

where $L$ is the applied load.

Figure 5(a) shows dry and oil-lubricated track widths for runs lasting $100 \mathrm{~m}$. It shows that track widths increase from the initial Hertz contact width rapidly for the dry test and less quickly for the oil-lubricated test, as expected. Figure 5(b) shows, in another way to present those results: for any given track width $(\mathrm{w})$ other than within the initial contact width, the sliding distance during the test is shorter the farther one moves from the center of the track. Physically, this concept is easy to understand, but the implication is that the edges of the track continue to run-in while the portion farther toward the center, has already reached a steady-state wear rate.

(insert Figures 5a and 5b) 
Interestingly, the popular Archard relationship, introduced in the 1950's [25] inherently presumes a linear relationship between sliding distance, load, hardness of the wearing body, and wear volume, but it fails to account for natural transitions. Despite this drawback, the Archard relationship is widely used to interpret pin-on-disk and other sliding wear data.

A subtler type of natural transition, in which the state of the wear track goes through a fourstage cycle of smoothing, roughening, and re-smoothing was proposed in 1981 [26]. This proposal is in contrast to that mentioned by Kragelski et al. [21] in which there is purported to be an 'equilibrium surface roughness' for a given tribosystem. The Kragelski phenomenon has an experimental basis in terms of smoother starting surfaces tend to get rougher and rougher starting surfaces tend to get smoother during running-in to approach a tribosystem specific characteristic steady-state roughness (the author prefers 'steady-state' to Kragelski's term 'equilibrium roughness').

There are more subtle changes that can occur cyclically in sliding metals, even after running-in. Figure 6 depicts a repeating sequence of changes in wear surface morphology that was proposed in an earlier paper [26]. In that case, a cyclic wear process within the highlydeformed layer (HDL) occurs. This kind of transition would not be expected to produce large variations in the IWR, but it does propose a means by which even a post-running-in, steady-state wear rate can experience periodic variations. In that sense, the notion of equilibrium roughness may reflect an average steady-state condition rather than the instantaneous condition.

\section{(insert Figure 6)}

The likelihood that periodic changes in the wear rate, like that shown in Figure 6, will occur depends on the details of how cracks initiate and grow within the HDL, and that in turn depends on the microstructure and properties of the HDL. Research has shown that the stacking fault energy of alloys affects their ability to form the near-surface substructure (dislocation cells, micro-twins, or amorphous areas) within the HDL (e.g., [27, 28]). Furthermore, as shown in Figure 7, materials slid under the same block-on-ring test conditions can develop different depths of the HDL. Since tribolayers like the HDL can differ in composition, microstructure, and depth, the processes of cyclic transitions such as that depicted in Figure 6, would also be expected to differ for different material pairs and regimes of lubrication. The thinner the lubricant film, the more evident would the effects of solid/solid contact.

\section{(insert Figure 7)}

With notable the exception of GTRF, the contact geometries and motions under discussion to this point, were relatively simple, like a unidirectional pin-on-disk test or two-body abrasion on a platen. However, when sliding motions become more complex and multi-directional, as it does in bio-implants for example, recent work suggests that it is better to normalize the wear by number of cycles than by the sliding distance [29]. Still, irrespective of the factors used in normalization, it is important to account for both sequential and parallel natural transitions if the materials in the tribosystem of interest are, by virtue of their structure and properties, prone to such behavior.

The onset of scuffing can serve here as a final illustration of sliding wear transitions. Studies of the scuffing tendencies of ceramics and hard coatings for possible use in diesel engine fuel injector plungers were conducted several years ago using a novel, reciprocating crossed- 
cylinders configuration [30]. The test method consisted of a upper cylindrical pin that oscillated with its axis perpendicular to two parallel lower pins of equal diameter. The purpose of that test was to investigate the likelihood of scuffing of various candidate material pairs lubricated by diesel fuel. Scuffing damage was monitored indirectly using friction coefficient changes relative to those captured at the same locations during the initial stroke. It was found that scuffing damage began at the end points of the stroke and progressed toward the center. The time to initiate and complete a transition from fully non-scuffed to fully-scuffed could then be estimated from the friction force data. In contrast to the pin (ball)-on-disk situation where the edges of the widening wear track were at an earlier stage of wear than the material at the center, in the pin-ontwin-pins case, the transition to a second steady-state (i.e., 'scuffed') began at the ends of the wear track and converged at the center. Figure 8 schematically compares the pin-on-disk and pin-on-twin situations. In the pin-on-twin example (b), only the scar on one of the lower twin cylinders has been depicted. Not only does the primary scuffing damage converge from the ends of the track toward the center in case (b), but also the width of the track increases. Considering these special cases, transitions can occur outward from the center of a contact, as in case (a) or both inward from the ends and outward from the mid-line, as in case (b).

\section{(insert Figure 8)}

\subsection{Discussion}

As shown in the foregoing examples, wear transitions are commonplace. They can manifest themselves in many different ways, ways that affect how wear rates are reported and how a material's suitability for a given application can be determined. While the specific reasons underlying transitions vary with the tribo-system, there are several general points that can be made about them and their implications for advancing the study of wear of materials.

\subsection{Challenges for the detection of wear transitions. The study of wear transitions} challenges experimental tribologists to develop accurate methods for in situ wear measurement. While calculating a SSWR using mass or volume changes requires only two measurements before and after testing, the study of transitions requires frequent, ideally continuous monitoring of wear. If continuous measurement is impractical, a second choice is to stop periodically to measure wear or to conduct tests of varying durations, presuming that any transitional behavior is repeatable from test-to-test. Sometimes transitions are highly repeatable [31]. When halting for periodic wear measurements, there is a possibility of inducing a transition inadvertently when reassembling the experiment in order to restart it. Thus, the challenge of devising accurate, repeatable methods for in situ wear measurement without disturbing the running conditions is an important consideration in transitions-focused research. Indirect wear measures like using friction force changes (in the example of scuffing), sudden heating, or changes in vibration or debris in the oil can be used to detect severe wear transitions, but the sensitivity of such indirect methods to detect and study subtle mechanistic changes in the steady-state wear process (like that in Figure 6) is limited.

3.2 Annotation of wear rates. For tribosystems that display wear transitions, it seems reasonable that the symbols used to report wear rates should be annotated accordingly. Standardized erosion testing, mentioned earlier in the paper, has already incorporated ways to do 
this, but in general, those who report sliding wear data, albeit with notable exceptions as in the work of Kragelski and other Russian authors [21], have been slow to address this point.

It is proposed that if wear measurements are made only at the end of an experiment and a normalized wear factor is presented (i.e., the SSWR), then a statement should be made in the documentation indicating either that the assumption of wear linearity has been made or that experimental verification of linear behavior has been done.

To account for possible transitions, a simple notation method is proposed. Letting $\mathrm{W}^{*}$ indicate the normalized wear rate of a specimen material, the format could be $\mathrm{W}^{*}$ [unit of duration $=$ starting point: end point $]$. For example:

$$
\begin{aligned}
& \mathrm{W}_{[\mathrm{x}=100: 1000]}=\text { wear volume } /(\text { load } \mathrm{x} \text { given distance interval }) \\
& \mathrm{W}_{[\mathrm{n}=2 \mathrm{kcyc}: 4 \mathrm{kcyc}]}=\text { wear volume } /(\text { load } \mathrm{x} \text { given range of cycles }) \\
& \mathrm{W}^{*}{ }_{[\mathrm{t}=5000: 6000]}=\text { wear volume } /(\text { load } \mathrm{x} \text { given time interval })
\end{aligned}
$$

The subscripts refer to the units of duration like cumulative sliding length in meters (x), number of back and forth strokes (n), or running time in seconds ( $\mathrm{t}$ ). If the SSWR is reported based on measurements of total wear at the end of the test or operating period, then the subscript would indicate the total duration rather than the range, such as $\mathrm{W}^{*}[\mathrm{t}=3600 \mathrm{~s}]$. Using such a simple approach to notation limits the reported wear rates to specific ranges in which steady-state is observed. However, this first-order approach still uses an average wear rate, albeit within the range of measurement and is still an approximation of the subtle details of wear progression that could be detected with better continuous measurements.

3.3 Modeling of wear transitions. Some transitions are more complex than others, but sliding wear tribosystems that exhibit two or more steady-states, each with a relatively constant wear rate, can be approximated by a simple multi-term model. If, for example, the total wear volume is $\mathrm{V}_{\mathrm{T}}$, then the wear volumes produced during stages 1 and 2 are $\mathrm{V}_{1}$ and $\mathrm{V}_{2}$, respectively. If the tribosystem runs under constant load $\mathrm{P}$ and sliding velocity $\mathrm{v}$, then after sliding a total distance of $\left(\mathrm{X}_{1}+\mathrm{X}_{2}\right)$, the wear volume is:

$$
\mathrm{V}_{\mathrm{T}}=\mathrm{V}_{1}+\mathrm{V}_{2}
$$

It is assumed that the wear volume of each stage is proportional to the total frictional work done during over the sliding distance for that stage. Unlike the typical approach of dividing the wear volume by the normal force $(\mathrm{P})$, this approach considers the frictional work (i.e., friction force (F) times sliding distance). Using frictional work rather than normal force times sliding distance, as is traditional, is felt to be a more accurate consideration of the use of energy available to wear the material. For stage 1, therefore, this term is,

$$
\mathrm{V}_{1}=\mathrm{k}_{1} \mathrm{~F}_{1} \mathrm{X}_{1}=\mathrm{k}_{1}\left(\mu_{1} \mathrm{P}\right)\left(\mathrm{vt}_{1}\right)
$$

where $\mu_{1}=$ the average sliding friction coefficient for stage 1 and $t_{1}$ is the time spent sliding during that stage. Thus, the total wear volume for a tribosystem that runs under constant load and speed at an initial wear rate of $\mathrm{k}_{1}$ and then a post-transition wear rate of $\mathrm{k}_{2}$ becomes: 


$$
\mathrm{V}_{\mathrm{T}}=\operatorname{Pv}\left[\left(\mu_{1} \mathrm{k}_{1} \mathrm{t}_{1}\right)+\left(\mu_{2} \mathrm{k}_{2} \mathrm{t}_{2}\right)\right]
$$

That basic, step-wise steady-state approach has been applied to model the grid-to-rod fretting of nuclear fuel rod cladding, described earlier [17], in which an oxide layer of lower wear rate and friction coefficient was worn through into a substrate of higher wear rate under a higher friction coefficient. The same kind of multi-stage modeling could be applied to approximate the wear behavior of other tribo-systems which exhibit multiple steady-states, each of which tends toward an average, characteristic wear rate and friction coefficient.

While addressing the nature of wear transitions complicates analysis, modeling, and experimental aspects of tribology, it can nevertheless represent a more realistic approach to the treatment of wear problems. Acknowledgement of multiple steady-states and investigating the fundamental causes for the transitions between these states provides new insights into the wear of materials.

\subsection{Summary}

Wear transitions, both induced and natural, are commonplace in a variety of practical tribosystems. The fact that such transitions occur implies that there are situations in which wear behavior cannot accurately be represented by a linear, normalized combination of units. Examples of transitions were provided for four different wear types: erosive wear, two-body abrasive wear, fretting wear, and sliding wear, including scuffing. The instantaneous wear rate (ISR) is that which occurs at a given point in component life, and a system-specific wear rate (SSWR) is a metric that can be used to compare the relative wear of engineering components for a fixed operating period, irrespective of the path taken to reach that point.

1) Improved monitoring of incremental wear behavior, and intermittent examinations of surfaces, will help to identify the nature of natural transitions.

2) Some transitions, like wear-through of a coating or fatigue failure, can be rapid and catastrophic, but others, like the degradation of abrasive paper by debris loading or attritious wear, can be more gradual.

3) One approach to reporting sliding wear data for systems suspected to undergo natural transitions is to fix the test parameters based on the intended application, then report only the wear volume or mass loss measured at that time without normalization. This system-specific wear rate (SSWR) can then be used as a pre-screening tool.

4) Transitions in surface damage can occur both sequentially and simultaneously, on different areas of the same wear scar. Contact geometry affects the occurrence of such phenomena.

5) Annotating wear rate symbols with a range of applicability can help to account for wear transitions when reporting data.

6) Tribosystems with multiple steady-states can be modeled using additive terms based on frictional work done. 
7) Research into the causes for changes in steady-state wear can provide new insights into the basic operation of wear mechanisms and their evolution.

\section{Acknowledgements}

A portion of the work described here was conducted while the author was employed at the U.S. National Bureau of Standards (now NIST) and Oak Ridge National Laboratory. The author appreciates the generous support of various sponsors from the U.S. Department of Commerce, the U.S. Department of Energy, the Department of Transportation, and his ASTM colleagues and past co-authors. A special acknowledgement is given to Prof. David A. Rigney (The Ohio State University, ret.) who introduced the author to the rich world of materials tribology, and Dr. Bill Ruff and Mr. Lew Ives (both NIST, ret.) who provided guidance during the early stage in my career where I explored transitional behavior and became involved with the hows and whys of standardization.

\section{References}

1. ASTM G40-13, Terminology Relating to Wear and Erosion, ASTM Annual Book of Standards, Vol. 03.02 (2013).

2. P. J. Blau, Friction and Wear Transitions of Materials: Break-in, Run-in, Wear-in, Noyes Pub., Park Ridge, NJ (1989).

3. M. B. Peterson, Design Considerations for Effective Wear Control, in Wear Control Handbook, ed. M. B. Peterson and W. O. Winer, ASME, New York, NY (1980), pp 413-473

4. ASM Committee on Analysis of Fatigue Failures, Fatigue Failures, ASM Handbook, Vol. 10, Failure Analysis and Prevention, 8th Ed., ASM International, Materials Park, OH (1975) 95-125.

5. L. Pook, Metal Fatigue: What it is, Why it Matters, Springer Pub., Series of Solid Mechanics and Its Applications, Vol. 145, (2007) 264 pp.

6. P. J. Blau, The units of wear revisited, Lubrication Engineering, 45 (1989) 609-614.

7. Proc. International Conference on Wear of Materials, Wear, Vol. 301 (Part 1), (2013).

8. F. J. Heymann, Liquid Impingement Erosion, in ASM Handbook, Vol. 18, Friction, Lubrication, and Wear Technology, ASM International (1992) pp. 221-232

9. ASTM G73-10, Standard Test Method for Liquid Impingement Erosion Using Rotating Apparatus, ASTM Annual Book of Standards, Vol. 03.02, ASTM International, W. Conshohocken, PA (2013), pp. 281-299 
10. I. M. Hutchings, Tribology - Friction and Wear of Engineering Materials, CRC Press, Boca Raton, FL 1992, p. 174

11. E. F. Tobin, D. Raps, O. Rohr, W. Willemse, P. Normam, and T.M. Young, (2014) Surface topography parameters as a correlation factor for liquid droplet erosion test facilities, Wear (2014) in press.

12. P. J. Blau and R.R. de Hoff. Development of a two-body wet abrasion test method with attention to the effects of reused abradant, Wear 302 (1-2) (2013) 1035-1039.

13. P. J. Blau, E. P. Whitenton, and A. Shapiro, Initial frictional behavior during the wear of steel, aluminum, and (poly)methylmethacrylate on abrasive papers, Wear 124(1) (1988) 1-20.

14. ASTM G174-04, Standard Test Method for Measuring Abrasion Resistance of Materials Using Abrasive Loop Contact, ASTM Annual Book of Standards, Vol. 03.02, ASTM International, W. Conshohocken, PA (2014) 735-741.

15. ASTM G132-96, Standard Test Method for Pin Abrasion Testing, ASTM Annual Book of Standards, Vol. 03.02, ASTM International, W. Conshohocken, PA (2014) 560-567.

16. R. B. Waterhouse, Fretting Corrosion, Pergamon Press Ltd., Oxford, UK (1972).

17. P. J. Blau, A multi-stage wear model for grid-to-rod fretting of nuclear fuel rods, Wear, 313 (1-2) (2014) 89-96.

18. D. Dowson, C. M. Taylor, and M. Godet, ed., The Running in Process in Tribology, Elsevier Pub. (1982).

19. P. J. Blau, Friction and Wear Transitions of Materials: Break-in, Run-in, Wear-in, Noyes Pub., Park Ridge, NJ (1989).

20. P. J. Blau, Running-in: Art or Engineering, J. Mater. Engr., 13 (1991) 47-53.

21. I. V. Kragelski, M. N. Dobychin, and V. S. Kombalov, Running-in and Equilibrium Surface Roughness, in Friction and Wear Calculation Methods, Pergamon Press, Oxford, UK (1982) 297-316.

22. P. J. Blau, The Use and Misuse of the Pin-on-Disk Wear Test, presented at the STLE Annual Meeting, Lake Buena Vista, Florida, May 2014.

23. K. R. Mecklenburg, The effect of wear on the compressive stress in the sphere-on-plane configuration, ASLE Trans., Vol. 17 (1974) 149.

24. O. Ajayi and R. Erck, Analysis of Sliding Wear Rate Variation with Nominal Contact Pressure, pres. ASME/STLE Joint Tribology Conference (2001), posted on the internet at http://www.ipd.anl.gov/anlpubs/2001/11/40860.pdf 
25. J. P. Archard, Contact and Rubbing of Flat Surfaces, J. Appl. Physics. 24 (8) (1953) 981988.

26. P. J. Blau, Mechanisms for transitional friction and wear behavior of sliding metals," Wear, Vol. 72 (1) (1981) 55-66.

27. P. J. Blau, Interrelationships Among Wear, Friction, and Microstructure in the Unlubricated Sliding of Copper and Several Single-Phase Binary Copper Alloys, Ph.D. Dissertation, The Ohio State U., Columbus, OH, (1979) 341 pp.

28. P. J. Blau, The Role of Metallurgical Structure in Sliding Solid Contacts, ASME Appl. Mechanics Div., Pub. AMD-39, Amer. Soc. of Mech. Engr., New York (1980) 185-191.

29. A Wang, R. Lee, L. Herrera, and L. Korduba, Modeling and verification of ultra-high molecular weight polyethylene wear in multi-directional sliding, Wear 301 (1-2) (2013) 162-167.

30. J. Qu, J. J Truhan, P. J. Blau, Detecting the Onset of Localized Scuffing with the Pin-onTwin Fuel-Lubricated Test for Heavy Duty Diesel Fuel Injectors," SAE International Journal of Engine Research, Vol. 6 (No. 1) (2005) 1-9.

31. P. J. Blau and R. L. Martin, Friction and wear of carbon-graphite materials against metal and ceramic counterfaces, Tribology International, Vol. 27 (6) (1994) 413-422. 
Tables

Table 1. Comparison of the metrics for reporting wear in two International Wear of Materials (WoM) Conferences (Source: [6,7])

\begin{tabular}{|c|c|c|c|}
\hline Form of wear & Unit dimensions & $\begin{array}{l}\text { Units of measure } \\
\text { (WoM 1987) }\end{array}$ & $\begin{array}{c}\text { Units of measure } * \\
\text { (WoM 2013) }\end{array}$ \\
\hline \multirow[t]{5}{*}{ Abrasive (2, 3 body) } & Mass loss & $\mathrm{g}$ & $\begin{array}{l}\mathrm{g}^{-1}(\text { wear resistance }) \\
\mathrm{mg}\end{array}$ \\
\hline & Scar dimensions & length, mm & $\begin{array}{l}\text { depth, } \mathrm{nm} \\
\text { depth, } \mu \mathrm{m}\end{array}$ \\
\hline & Volume loss & $\mathrm{mm}^{3}$ & $\mu \mathrm{m}^{3}[3]$ \\
\hline & $\begin{array}{l}\text { Combinations of } \\
\text { units }\end{array}$ & $\begin{array}{l}\mathrm{cm}^{3} / \mathrm{kg} \\
\mathrm{mg} / \mathrm{N}-\mathrm{m} \\
\mathrm{mm}^{3} / \mathrm{m} \\
\mathrm{mm}^{3} / \mathrm{min} \\
\mathrm{mm}^{3} / \mathrm{N}-\mathrm{m} \\
\mathrm{N}-\mathrm{m} / \mathrm{mm}^{3} \text { (wear resist.) }\end{array}$ & $\begin{array}{l}\mathrm{mm}^{3} / \mathrm{N}-\mathrm{m} \\
\mathrm{N}-\mathrm{m} / \mathrm{mm}^{3} \text { (wear resist.) } \\
\mathrm{m}^{3} / \mathrm{m} \\
\text { "degree of wear" considers } \\
\text { displaced versus } \\
\text { removed material in a } \\
\text { groove } \\
\mathrm{m}^{2} / \mathrm{N} \text { (reduced from } \mathrm{m}^{3} / \mathrm{N}- \\
\mathrm{m} \text { ) }\end{array}$ \\
\hline & $\begin{array}{l}\text { Non-dimensional } \\
\text { combinations }\end{array}$ & $\begin{array}{l}\text { relative to a ref. mat'l. } \\
\text { Archard wear coeff. K } \\
\text { Product of: } \\
\quad \text { (mass*density*sliding } \\
\text { distance* contact area) } \\
\text { or its inverse }\end{array}$ & \\
\hline \multirow[t]{2}{*}{ Cavitation } & Mass loss & $\mathrm{N} / \mathrm{R}^{* *}$ & $\begin{array}{l}\mathrm{mg}[3] \\
\mathrm{g}\end{array}$ \\
\hline & Mass loss/time & $\mathrm{N} / \mathrm{R}$ & $\mathrm{mg} / \mathrm{h}$ \\
\hline \multirow[t]{7}{*}{ Erosive wear } & Mass loss & $\begin{array}{l}\mathrm{g} \\
\mathrm{mg} \\
\end{array}$ & \begin{tabular}{|l|}
$\mathrm{g}[3]$ \\
$\mathrm{mg}$ [3]
\end{tabular} \\
\hline & $\begin{array}{l}\text { Mass loss/mass of } \\
\text { erodant }\end{array}$ & $\begin{array}{l}\mathrm{g} / \mathrm{g} \\
\mathrm{mg} / \mathrm{g}\end{array}$ & $\begin{array}{l}\mathrm{g} / \mathrm{g} \\
\mathrm{mg} / \mathrm{Kg}\end{array}$ \\
\hline & Volume loss & $\begin{array}{l}\mathrm{mm}^{3} \\
\mathrm{~cm}^{3}\end{array}$ & $\mathrm{~mm}^{3}$ \\
\hline & Volume/unit erodant & $\begin{array}{l}\mathrm{mm}^{3} / \mathrm{g} \\
\mathrm{cm}^{3} / \mathrm{g} \\
\mathrm{m}^{3} / \mathrm{g}\end{array}$ & $\begin{array}{l}\mathrm{mm}^{3} / \mathrm{g} \\
\mathrm{g} / \mathrm{mm}^{3} \text { (resistance) }\end{array}$ \\
\hline & Dimensional change & depth, $\mu \mathrm{m}$ & depth, $\mu \mathrm{m}$ \\
\hline & Loss/time & $\begin{array}{l}\mathrm{g} / \mathrm{h} \\
\mathrm{g} / \mathrm{m}-\mathrm{h} \\
\mathrm{mm} / \mathrm{h}\end{array}$ & $\begin{array}{l}\mathrm{mg} / \mathrm{h} \\
\mathrm{mm}^{3} / \mathrm{s} \\
\mathrm{s} / \mathrm{mm}^{3} \text { (resistance) }\end{array}$ \\
\hline & Relative loss & $\begin{array}{l}\text { relative to a reference } \\
\text { material }\end{array}$ & $\begin{array}{l}\text { mass loss normalized to } \\
\text { total mass loss ( } \% \text { of } \\
\text { final wear amount) }\end{array}$ \\
\hline \multirow[t]{3}{*}{ Fretting wear } & Depth & $\mathrm{N} / \mathrm{R}$ & $\begin{array}{l}\mathrm{mm} \\
\mu \mathrm{m} \\
\mu \mathrm{m}(\text { crack depth })\end{array}$ \\
\hline & Mass loss & $\mathrm{N} / \mathrm{R}$ & $\mathrm{mg}$ \\
\hline & Volume loss & $\mathrm{N} / \mathrm{R}$ & $\begin{array}{l}\mu \mathrm{m}^{3} \\
\mathrm{~mm}^{3} \\
\mathrm{~m}^{3} \text { (both test specimens) }\end{array}$ \\
\hline
\end{tabular}




\begin{tabular}{|c|c|c|c|}
\hline & Combined units & $\mathrm{N} / \mathrm{R}$ & $\begin{array}{l}\mu \mathrm{m}^{3} / \mathrm{N}-\mathrm{m} \\
\mu \mathrm{m}^{3} / \mathrm{N}-\mu \mathrm{m} \\
\mathrm{mm}^{3} / \mathrm{N}-\mathrm{m} \\
\mathrm{mm}^{3} / \mathrm{mm}\end{array}$ \\
\hline & $\begin{array}{l}\text { Other measures of } \\
\text { wear }\end{array}$ & $\mathrm{N} / \mathrm{R}$ & $\begin{array}{l}\text { electric contact resistance } \\
\text { normalized pitting severity } \\
\text { (max. depth of pits on } \\
\text { both specimens) }\end{array}$ \\
\hline \multirow[t]{2}{*}{ Impact wear } & Depth & $\mathrm{N} / \mathrm{R}$ & $\mu \mathrm{m}$ \\
\hline & Volume loss & $\mathrm{N} / \mathrm{R}$ & $\mathrm{mm}^{3}$ \\
\hline \multirow[t]{3}{*}{ Impact with abrasion } & Mass loss & $\mathrm{N} / \mathrm{R}$ & $\mathrm{g}$ \\
\hline & Depth & $\mathrm{N} / \mathrm{R}$ & $\mu \mathrm{m}$ \\
\hline & $\begin{array}{l}\text { Volume/unit } \\
\text { abradant }\end{array}$ & $N / R$ & $\mathrm{mg} / \mathrm{Kg}$ \\
\hline Scuffing & Critical condition & $\mathrm{N} / \mathrm{R}$ & $\begin{array}{l}\mathrm{N} \text { (critical load) } \\
\mathrm{N}-\mathrm{m} \text { (load and sliding } \\
\text { distance for friction } \\
\text { coeff. to exceed } 0.2 \text { ) }\end{array}$ \\
\hline \multirow[t]{9}{*}{ Sliding wear } & Mass loss & $\begin{array}{l}\mu \mathrm{g} \\
\mathrm{mg} \\
\mathrm{g}\end{array}$ & $\begin{array}{l}\mathrm{mg}[3] \\
\% \text { mass loss }\end{array}$ \\
\hline & Volume loss & $\begin{array}{l}\mu \mathrm{m}^{3} \\
\mathrm{~mm}^{3}\end{array}$ & $\begin{array}{l}\mu \mathrm{m}^{3} \\
\mathrm{~mm}^{3}[12] \\
\end{array}$ \\
\hline & Depth & $\begin{array}{l}\mu \mathrm{m} \\
\mathrm{mm}\end{array}$ & $\begin{array}{l}\mu \mathrm{m} \\
\mathrm{mm} \\
\mathrm{nm} \\
\text { pin displacement, } \mathrm{mm} \\
\end{array}$ \\
\hline & $\begin{array}{l}\text { Surface roughness } \\
\text { due to wear }\end{array}$ & $\mathrm{N} / \mathrm{R}$ & $\begin{array}{l}\mu \mathrm{m} \\
\mathrm{nm}\end{array}$ \\
\hline & Loss/distance & $\begin{array}{l}\mathrm{g} / \mathrm{m} \\
\mathrm{mg} / \mathrm{cm} \\
\mathrm{mg} / \mathrm{m} \\
\mu \mathrm{g} / \mathrm{m} \\
\mathrm{mm}^{3} / \mathrm{cm} \\
\mathrm{mm}^{3} / \mathrm{mm}\end{array}$ & $\begin{array}{l}\mathrm{g} / \mathrm{m} \\
\mathrm{mg} / \mathrm{m} \\
\mathrm{mm}^{3} / \mathrm{mm} \\
\mu \mathrm{m}^{3} / \mathrm{mm}[2] \\
\mathrm{mm}^{3} / \mathrm{m}[2]\end{array}$ \\
\hline & $\begin{array}{l}\text { Loss/cycle } \\
\text { (revolution) }\end{array}$ & $\begin{array}{l}\mathrm{cm}^{3} / \text { kcyc } \\
\mu \mathrm{g} / \text { revolution }\end{array}$ & mm3/cyc [2] \\
\hline & Loss/time & $\begin{array}{l}\mu \mathrm{m} / \mathrm{min} \\
\mu \mathrm{m} / \mathrm{h} \\
\mathrm{mm} / \mathrm{s}\end{array}$ & $\mu \mathrm{m} / \mathrm{h}$ \\
\hline & $\begin{array}{l}\text { Dimensional } \\
\text { combinations }\end{array}$ & $\begin{array}{l}\mathrm{g} / \mathrm{cm}^{2}-\mathrm{s} \\
\mathrm{mm} 2 / \mathrm{N} \\
\mathrm{mm} 3 / \mathrm{N}-\mathrm{m} \\
\mathrm{mm} 3 / \mathrm{N}-\mathrm{mm}\end{array}$ & $\begin{array}{l}\mathrm{mm}^{3} / \mathrm{N}-\mathrm{m}[8] \\
\mathrm{m}^{3} / \mathrm{N}-\mathrm{m}[4]\end{array}$ \\
\hline & Non-dimensional & $\begin{array}{l}\text { Archard wear coefficient } \\
\mathrm{K}\end{array}$ & \\
\hline
\end{tabular}

* Number of papers in which this unit was used is shown in brackets [ ]. Based on the papers in the first of two volumes in the conference proceedings.

** NR means not reported in the cited reference 
Table 2. Effects of abradant wear on the wear rate of an experimental alloy steel during successive $50 \mathrm{~m}$ sliding runs on the same abrasive paper (data from [12]).

\begin{tabular}{|c|c|c|c|c|c|}
\hline Increment & $\begin{array}{c}\text { Mass loss } \\
(\mathrm{mg})\end{array}$ & $\begin{array}{c}\text { Cumulative } \\
\text { sliding distance } \\
(\mathrm{m})\end{array}$ & $\begin{array}{c}\text { Incremental } \\
\text { wear rate, Wi } \\
(\mathrm{mg} / \mathrm{m})\end{array}$ & $\begin{array}{c}\text { Cumulative } \\
\text { wear rate Wc } \\
(\mathrm{mg} / \mathrm{m})\end{array}$ & Wc/Wi (\%) \\
\hline 1 & 32.5 & 50 & 0.65 & 0.65 & 100.0 \\
\hline 2 & 25.0 & 100 & 0.50 & 0.58 & 88.5 \\
\hline 3 & 28.0 & 150 & 0.56 & 0.57 & 87.7 \\
\hline 4 & 18.3 & 200 & 0.37 & 0.52 & 79.8 \\
\hline 5 & 17.0 & 250 & 0.34 & 0.48 & 74.3 \\
\hline
\end{tabular}


Figure captions;

Figure 1. Common form of liquid droplet erosion versus time behavior. In this case, the ISWR would be difficult to measure since the slope of the plot changes frequently. Adapted from [8].

Figure 2. Multi-stage model for fretting wear of nuclear reactor components, based on two natural transitions (adapted from [17]).

Figure 3. Two sample cases of non-linear sliding wear behavior. Curve "B" accounts for a zero wear stage in which surface and subsurface damage is building up, but no material has yet been lost. Other curve shapes exist, but this is a common one.

Figure 4. Volumetric wear rate $\mathrm{W}$ depends on the starting and end points selected for the measurement in a hypothetical experiment represented by a dashed line. The IWR is the slope of the tangent to the wear curve at the X value of interest, and the SSWR is the slope of the line OA.

Figure 5. Calculation of the wear track width (w) with sliding distance (X) for dry and lubricated 52100 steel in a rounded pin-on-disk configuration. (a) showing the width of the track with sliding distance, (b) showing the sliding distance for various locations on the track width. In (a) $\mathrm{w}_{\mathrm{H}}$ is the Hertzian contact width (starting value at the stated normal loads).

Figure 6. One scenario for the progression of cyclic natural transitions during sliding wear of metals (based on Ref. [26]).

Figure 7. Thicknesses of highly deformed layers measured in cross-sections of block specimens of different materials slid under the same load and speed in non-lubricated, block-on-ring tests [28].

Figure 8. Comparison of a transition to severe wear during track widening in unidirectional a pin-on-disk test (a) and a convergent scuffing transition generated by a reciprocating upper cylinder on a lower cylinder (the scar on only one of the two lower cylinders is depicted). 


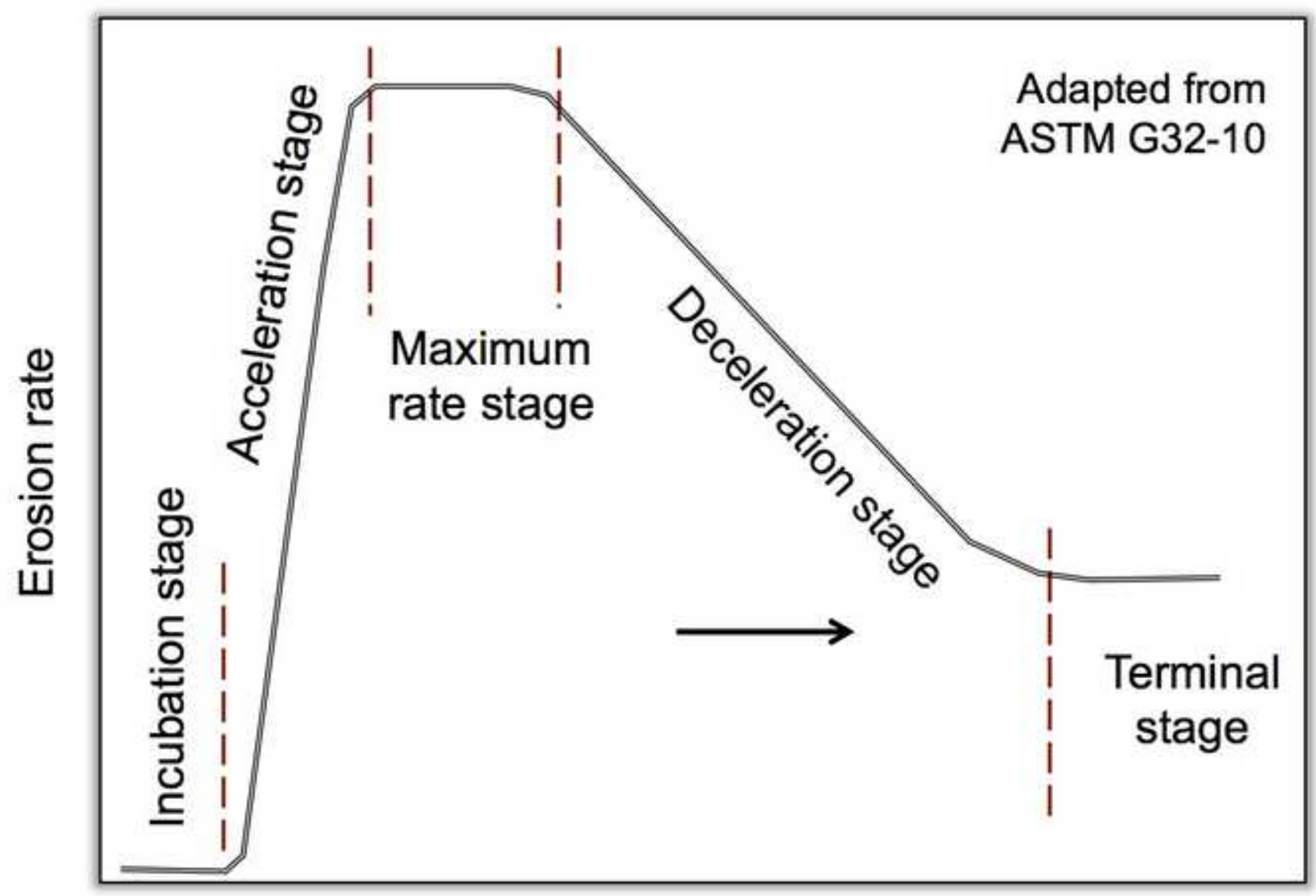

Exposure time 


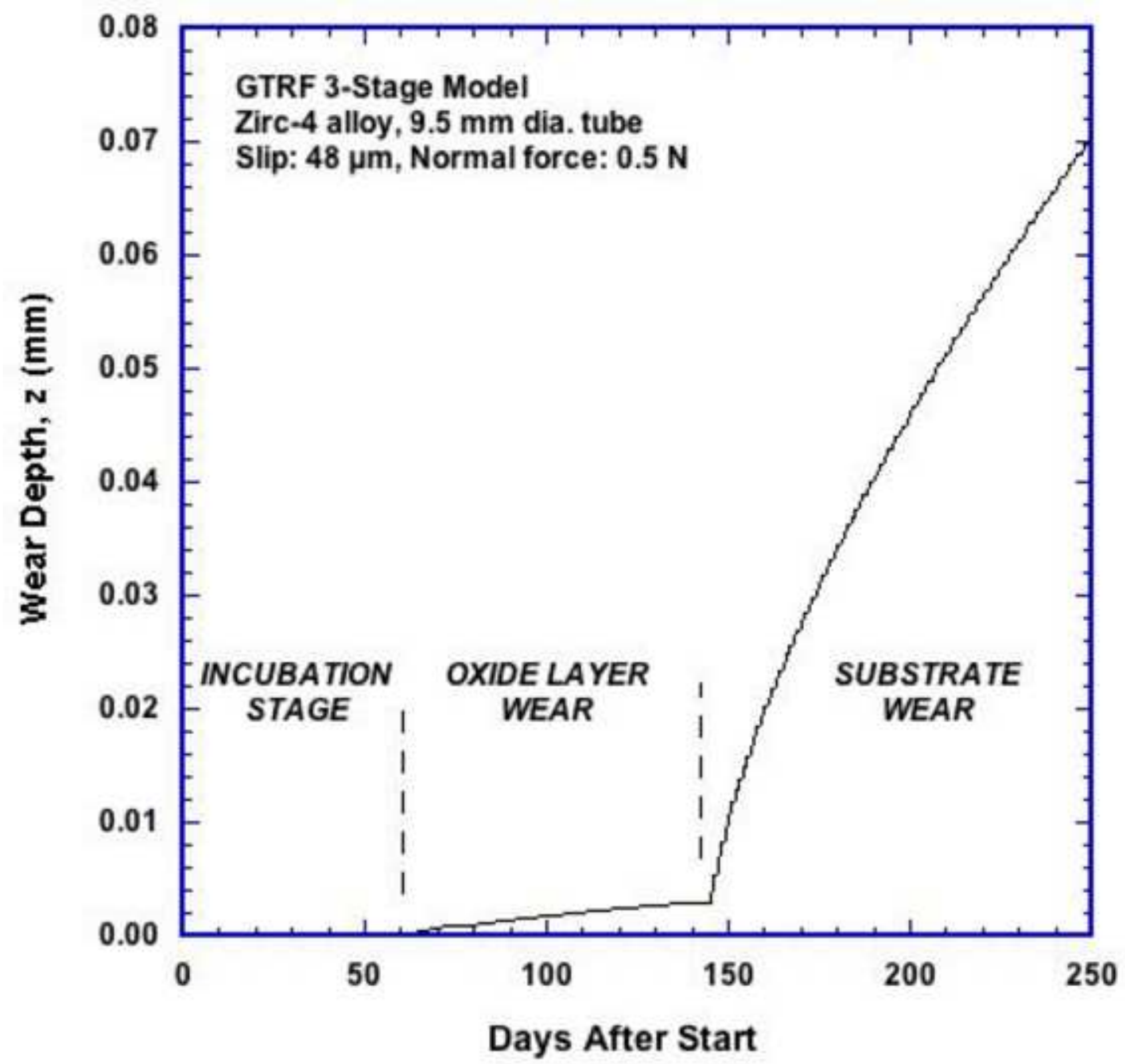




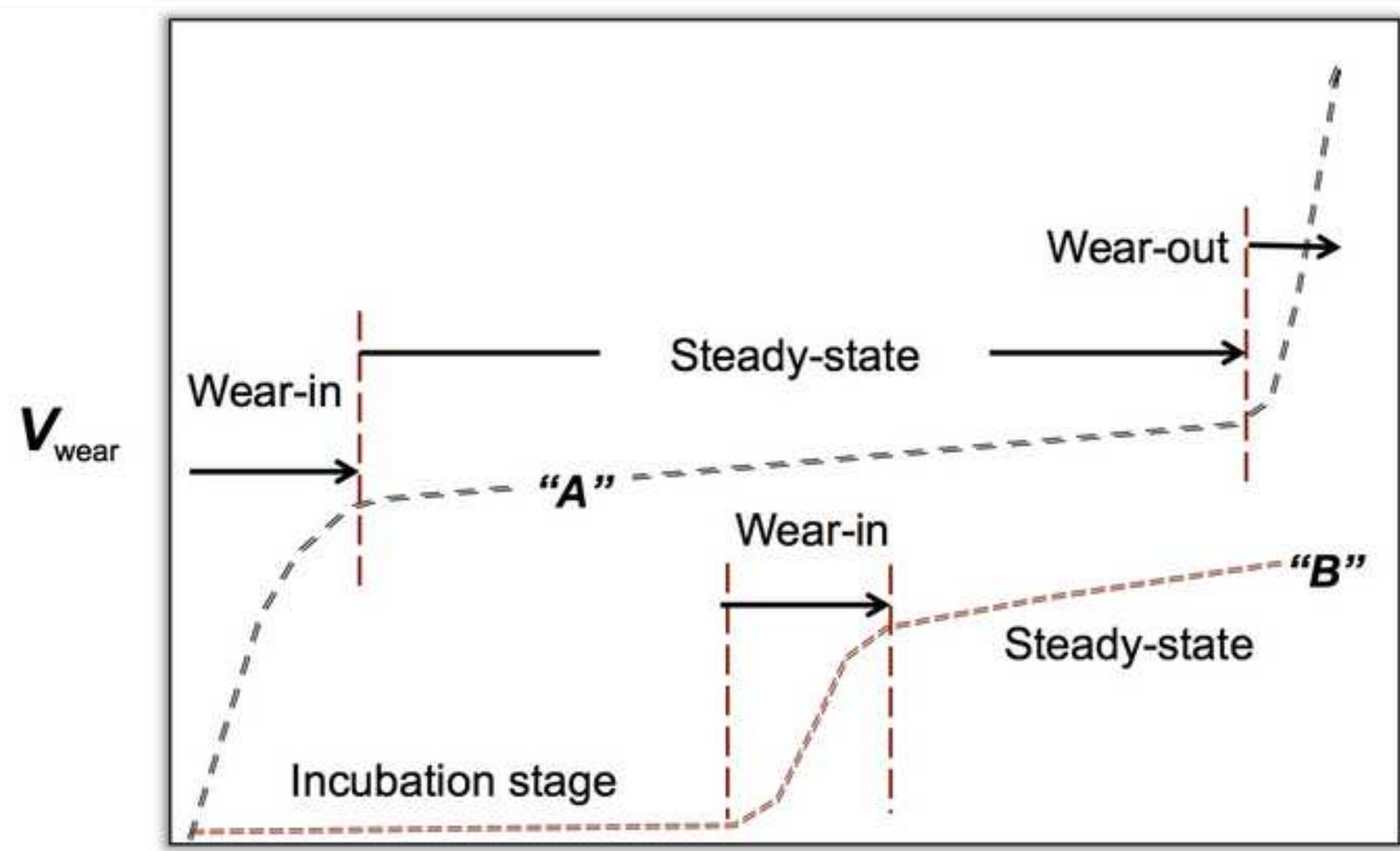

Duration: cycles, time, distance 


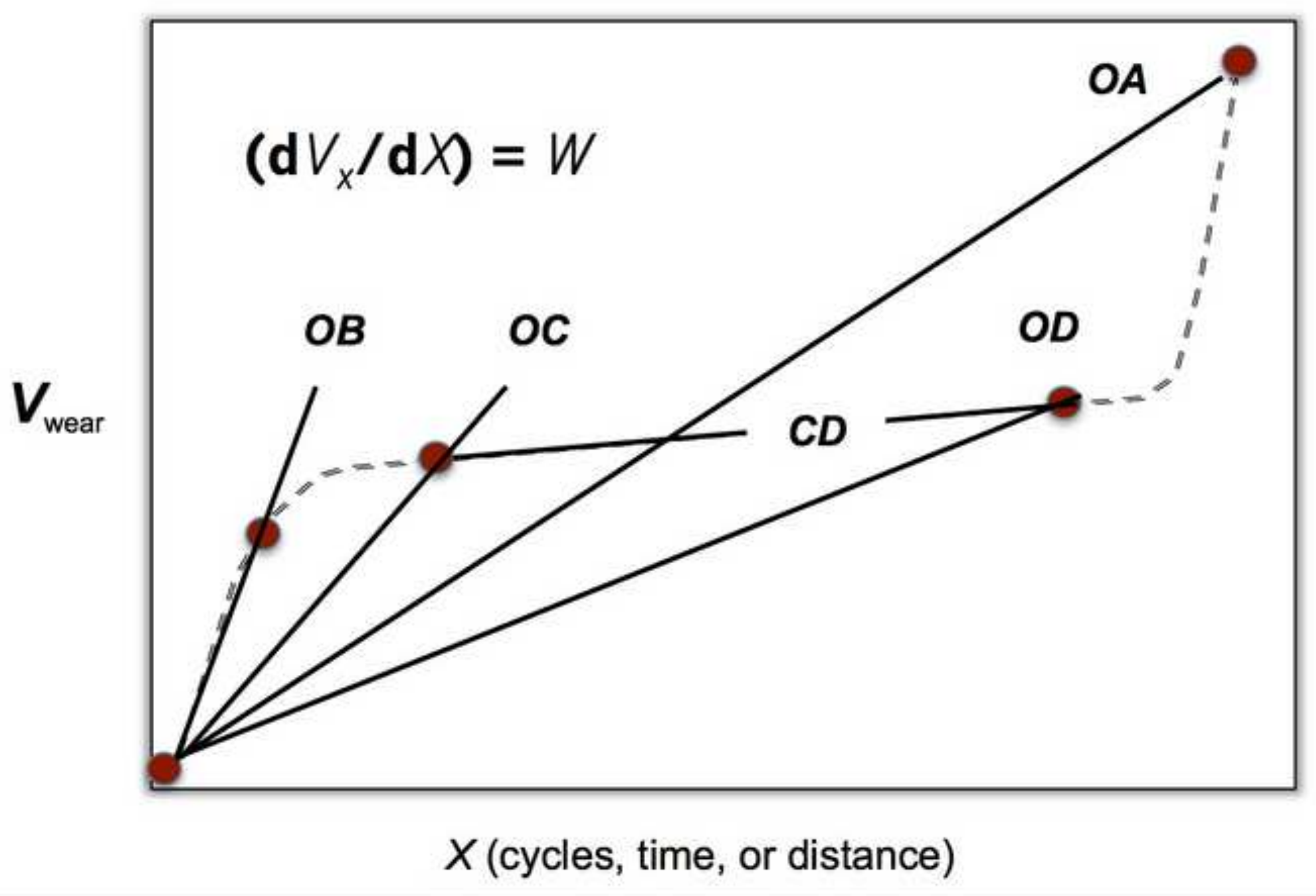




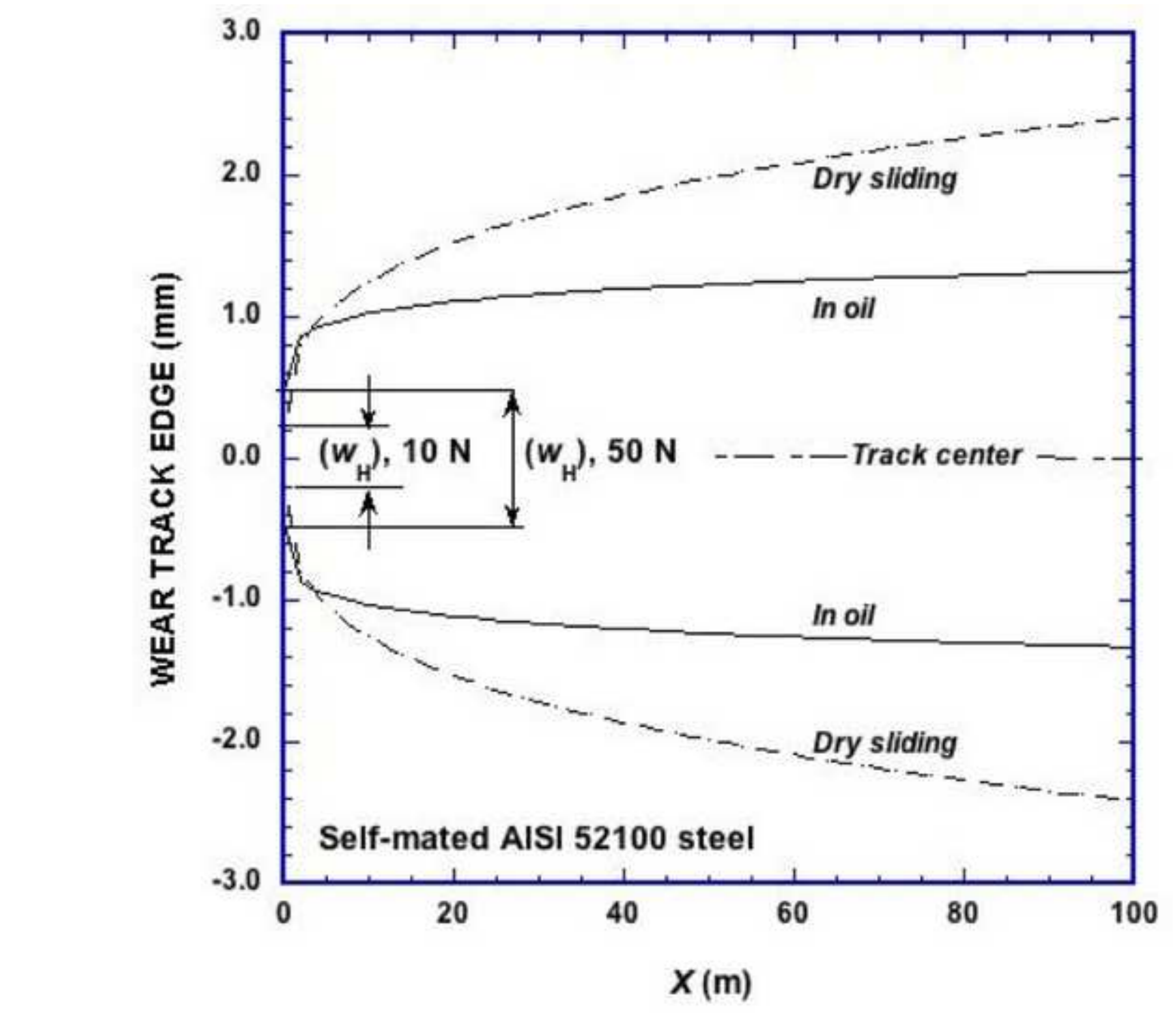


Figure 5b

52100 STEEL

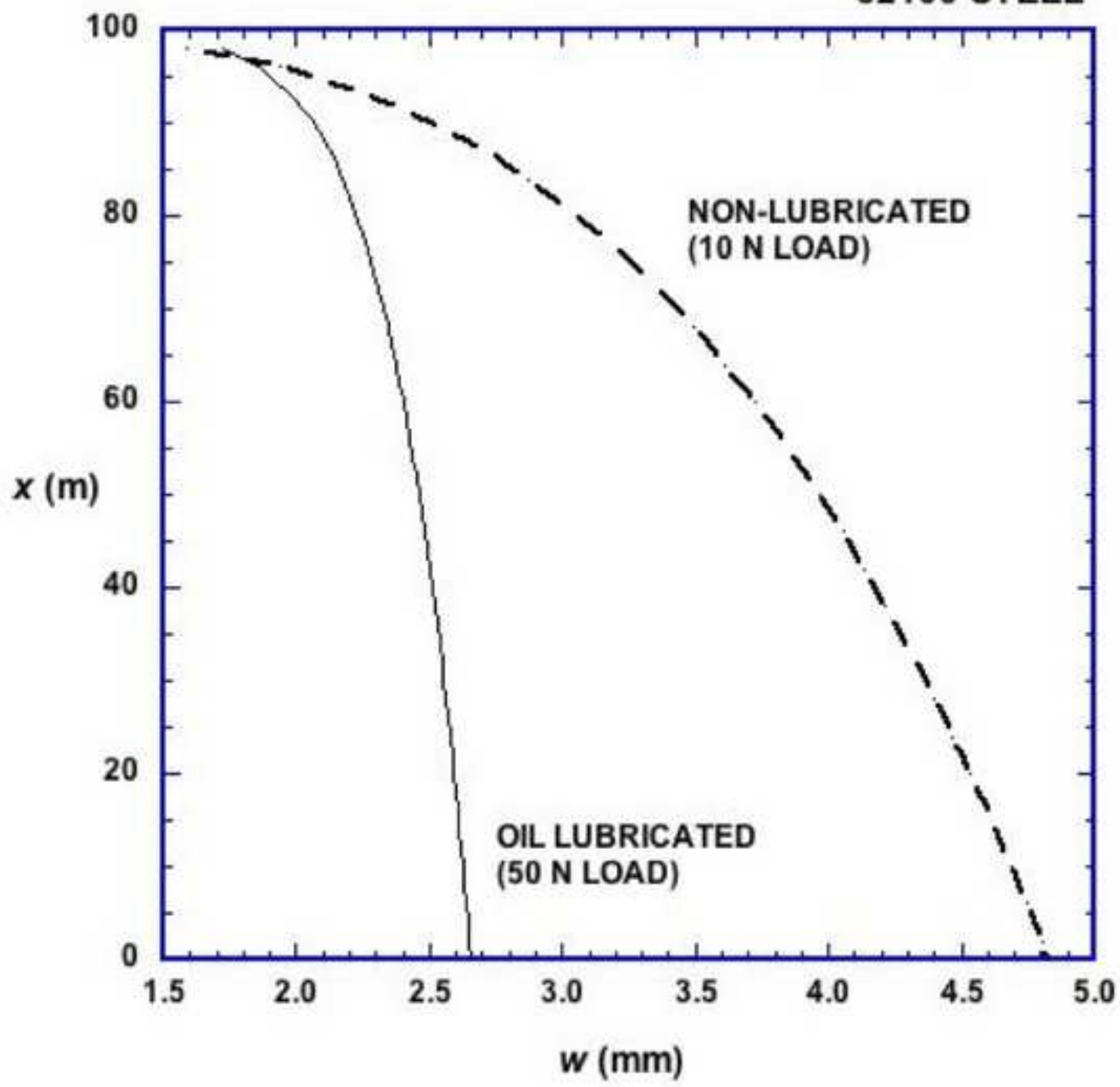




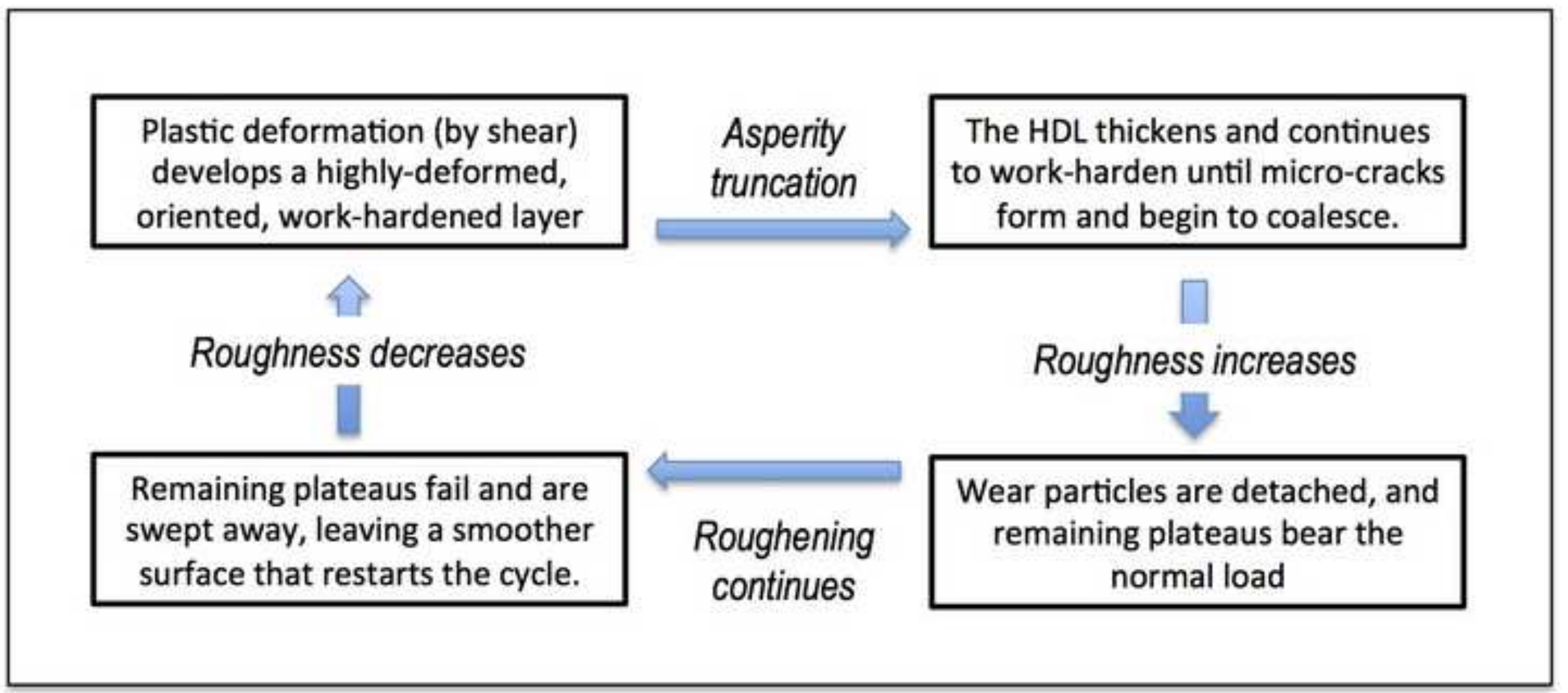




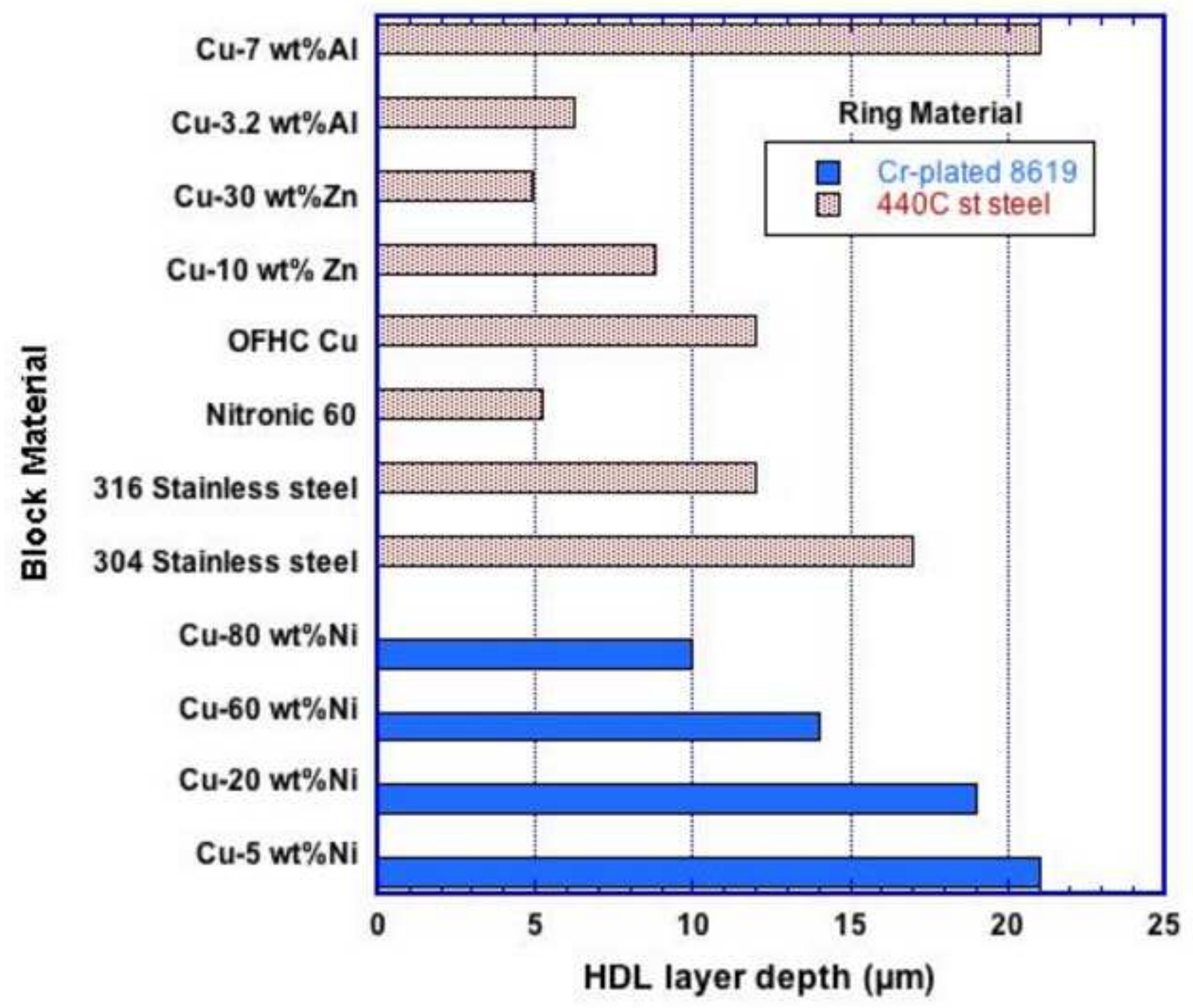


